\title{
Antitubercular Agent
}

National Cancer Institute

\section{Source}

National Cancer Institute. Antitubercular Agent. NCI Thesaurus. Code C280.

Any agent that is active against Mycobacterium tuberculosis and can be used in the treatment of or in the prevention of tuberculosis. 